\title{
Radical Surgical Management of Perianal Giant Condyloma Acuminatum of Buschke and Löwenstein: Long-term Results of 11 Cases
}

\author{
Alp Yildiz ${ }^{1}$, Sezai Leventoglu², Aybala Yildiz ${ }^{1}$, Arda Inan ${ }^{3}$, Bedrettin Bulent Mentes ${ }^{4}$ \\ ${ }^{1}$ Department of General Surgery, Yenimahalle Training and Research Hospital, Ankara; Departments of ${ }^{2}$ Surgery and ${ }^{3}$ Pathology, Faculty of \\ Medicine, Gazi University, Ankara; ${ }^{4}$ Department of Surgery/Proctology, Memorial Ankara Hospital, Ankara, Turkey
}

Purpose: Perianal Buschke-Löwenstein tumor (BLT) is characterized by an exophytic cauliflower-like mass surrounding the perianal region. Its tendency to infiltrate the adjacent tissues, its massiveness, and its high recurrence rate cause difficulties in treatment. The aim of this study is to report our strategy with wide local excision and flap reconstruction for BLT.

Methods: From November 2002 to June 2019, 11 patients (9 males) with a mean age of 33.45 years (range, 19-54 years) were operated on for BLT. All patients underwent wide local excision and V-Y flap reconstruction, supplemented with other flaps whenever needed. No additional modalities were used.

Results: Two patients had a history of anal intercourse while all patients were human immunodeficiency virus-negative. The mean tumor length was $15.54 \pm 1.34 \mathrm{~cm}$ (range, 10-26 cm). Human papillomavirus 6 was the most common type identified. Partial wound dehiscence developed in 3 patients, while anal stenosis, mucosal ectropion, or local recurrence was not observed during the mean follow-up period of 50.45 \pm 1.75 months (range, 10-196 months).

Conclusion: In patients with perianal BLT, wide local excision and flap reconstruction result in a high healing rate without significant complications.

Keywords: Buschke-Lowenstien tumor; Condylomata acuminata; Reconstructive; Surgical procedures; Colorectal surgery

\section{INTRODUCTION}

Giant condyloma acuminatum or Buschke-Löwenstein tumor (BLT) is a very rare, sexually transmitted disease caused by-particularly 6 or 11 type-human papillomavirus (HPV), with an overall infection rate of $0.1 \%$ and show male predominance. The presence of HPV in cervical smears is considered a risk factor for anal HPV. In men, the prevalence of anogenital HPV ranges from

Received: Jan 25, 2021 - Revised: Jul 12, 2021 - Accepted: Jul 12, 2021 Correspondence to: Aybala Yildiz, M.D.

Department of General Surgery, Yenimahalle Training and Research Hospital, 06500 Yenimahalle, Ankara, Turkey

Tel: +90-312-5872000, Fax: +90-312-2025747

E-mail: draybalayildiz@gmail.com

ORCID: https://orcid.org/0000-0002-7894-6846

(C) 2021 The Korean Society of Coloproctology

This is an open-access article distributed under the terms of the Creative Commons Attribution NonCommercial License (https://creativecommons.org/licenses/by-nc/4.0) which permits unrestricted noncommercial use, distribution, and reproduction in any medium, provided the original work is properly cited.
$1.3 \%$ to $72.9 \%$. In the case of anal intercourse, these rates increase in both sexes $[1,2]$.

BLT is characterized by its degenerative character, invasive potential, and high recurrence rates following treatment. It is thought to be histologically benign, even though its clinical features suggest the opposite, and give the impression that it is an intermediate entity between an ordinary condyloma acuminatum and squamous cell carcinoma (SCC) $[3,4]$. Its tendency to infiltrate the adjacent tissues, its massiveness, and its high recurrence rate bring along difficulties in treatment.

Several treatments have been tried, including electrocoagulation, laser, cryotherapy, radiotherapy, immunotherapy, systemic or local chemotherapy; however, the numbers are small, and considerable recurrences or treatment failures happen $[3,5-10]$. The proximity of the disease to the anal verge and the small number of patients reported put further shade on determining a specific and satisfying treatment strategy. Although treatment is poorly codified, the common and reasonable deduction has been that surgery 
is the leading choice $[11,12]$.

As a referral team, we have treated BLT assuming it's a low-grade malignant skin lesion. Weve performed radical excisions with apparently safe margins, and we have tailored flap reconstructions at the same session in order to leave no bare areas behind. With this study, which will be the largest series of BLT in literature, our aim was to demonstrate the efficacy and safety of wide resection and flap reconstruction for BLT.

\section{METHODS}

This is a retrospective analysis of a prospectively maintained database complemented by chart review with Institutional Review Board (No. 20-1452). We report 11 patients who underwent surgery from November 2002 to June 2019 for a BLT of the anal margin by the same surgical team. We analyzed the results of primary surgery, early and long-term complications, and recurrence. Recurrence was clinically evaluated and defined as any existing/ new condylomatous lesions on the perianal region at any followup period. Colonoscopy and pelvic magnetic resonance imaging were performed selectively, but rectoscopy and vaginal examination in females were routinely done. Biopsies were taken from ulcerated parts of the lesion in only 2 patients, none of which revealed malignancy.

For all patients, our team planned, tailored, and drew the excision patterns and possible flap reconstructions preoperatively. Our main purpose was to excise the perianal mass with apparently negative surgical margins. All patients underwent bowel prep preoperatively. Under epidural anesthesia and in prone jackknife position, the pattern of excision and possible flap reconstruction was reevaluated and marked. Resection with clearly safe margins (at least $1 \mathrm{~cm}$ ) and involving the subcutaneous fatty tissue was performed using the cut/blended mode of electrocautery. Meticulous dissection from the external anal sphincter was accomplished in most patients. After excision of the mass, the excised area was reconstructed preferably with fascia-cutaneous $\mathrm{V}-\mathrm{Y}$ advancement flaps that were created from both gluteal regions adjacent to the wound (Fig. 1). The jackknife position and taping were gradually released before suturing the flaps. Some patients required additional resection-primary repair, S-flaps, or island flaps for lesions extending to the vulva or perineum and/or to support the V-Y flaps for a tension-free reconstruction (Fig. 2). Very rarely, small bare areas had to be left behind. Additional focal lesions (warts) were noted in 3 patients in the anal canal, pubis, and/or penis, and these were removed separately. For some cases, Penrose or vacuum drains were inserted below the flaps and removed in 2 days. Postoperative pain management is performed with nonsteroidal anti-inflammatory drugs.

A low-fiber diet was ordered for 1 week postoperatively. A healthy diet and cessation of smoking, alcohol intake, and erratic sexual activity were emphasized. The partners of all patients were also invited for examination. The HPV vaccine was given to the 4 latest patients, as it is recommended for women or men under the age of 30 years and who are sexually active [1]. The patients were examined 2 weeks after discharge, at 2, 6, 12 months postoperatively, and then on a yearly basis. This follow-up was bent after 5
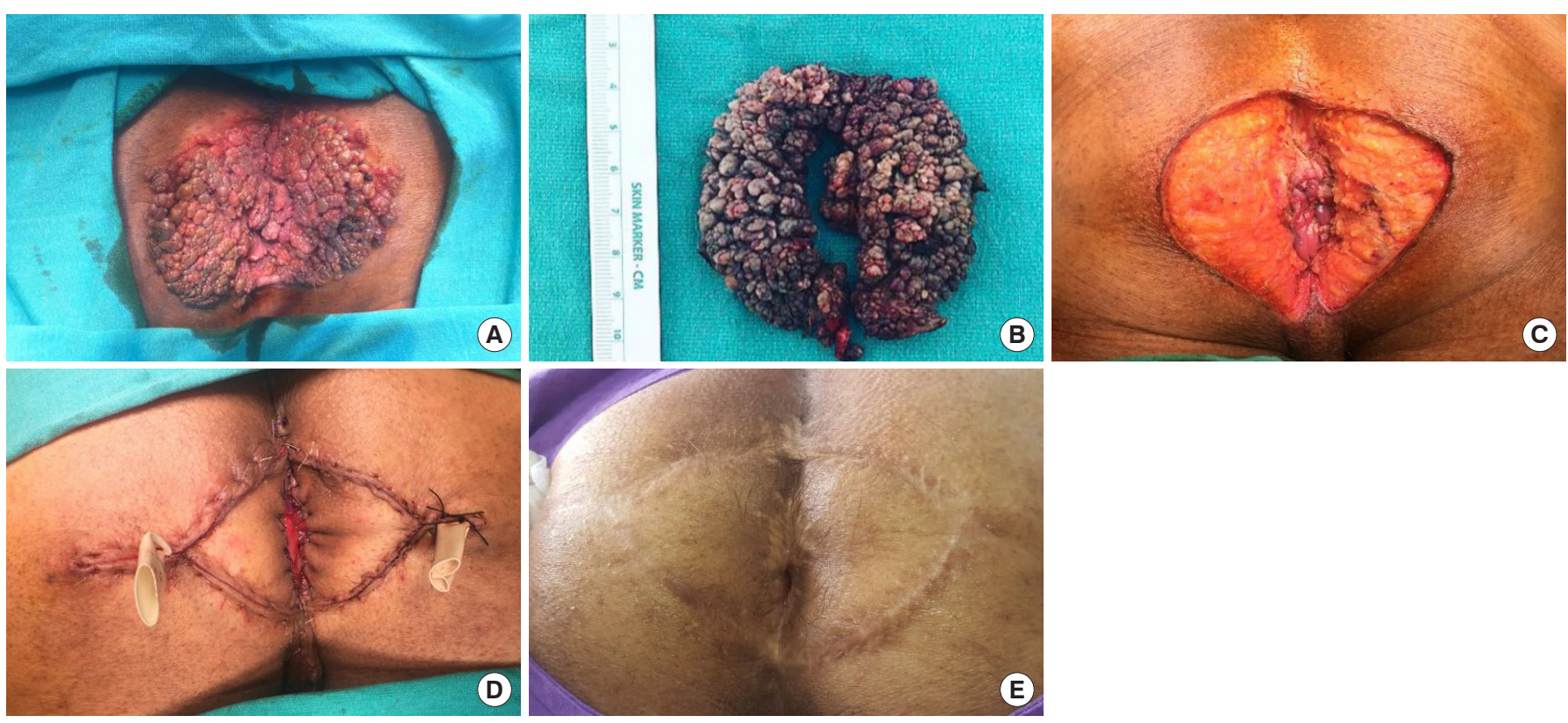

Fig. 1. (A) Typical Buschke-Löwenstein tumor. (B) The specimen. (C) Wide resection designed to be reconstructed with V-Y flaps. Simultaneous reconstruction with bilateral V-Y flaps (D) and healing at 3 years (E). 

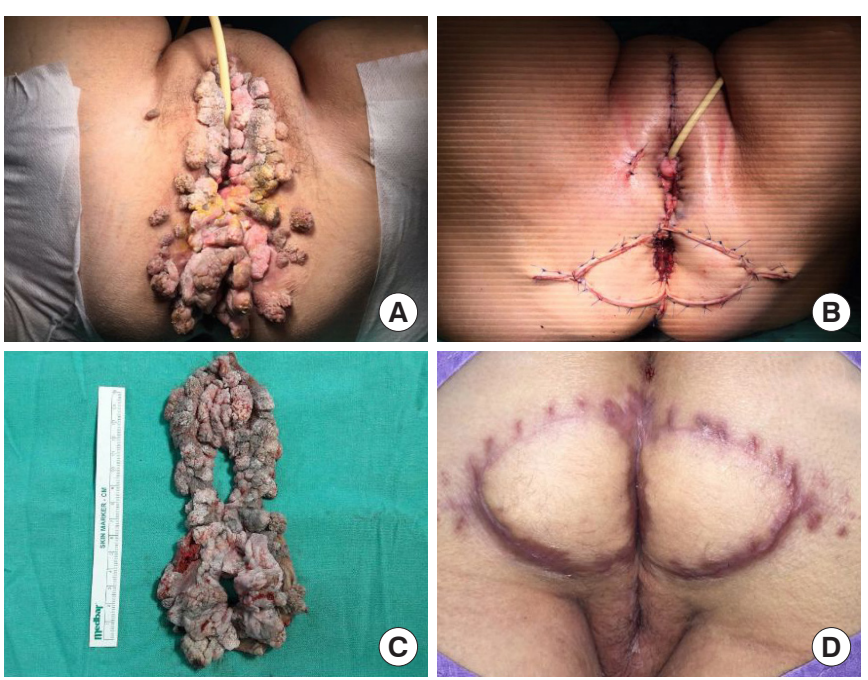

Fig. 2. (A) Extensive perianal and vulvar Buschke-Löwenstein tumor. (B) Reconstruction of the perianal region/defect with V-Y flaps and reconstruction of the vulva with primary repair and rotation flaps. (C) The specimen. (D) Healing at 1 year.

years, checking with telephone contact and asking patients to apply if they developed any lesions/problems; however, we examined them all before writing this series. Patients with wound dehiscence or other complications required more frequent visits. Two dedicated pathologists reviewed the pathology slides. Histological type, degree of dysplasia, specimen margins, and molecular classification of HPV according to the recommendations of the College of American Pathologists LAST project and latest World Health Organization classification were determined [13, 14]. Five micron sections from the tissue were evaluated for the presence of HPV DNA by in situ hybridization. Both Ventana Inform HPV II Family 6 and Family 16 Probes (Ventana Medical Systems, Tucson, AZ, USA) were applied. Family 6 probe demonstrates positive results with low-risk genotypes such as 6 and 11, while family 16 probe demonstrates positivity with subtypes 16 , $18,31,33,35,45,52,56,58$, and 66 . Polymerase chain reaction testing for HPV was not conducted since the recognition of highrisk group HPV existence is enough according to up-to-date guidelines [15]. Some of the former specimens were reevaluated at the time of manuscript enrollment. This study was approved by Institutional Review Board of the Memorial Ankara Hospital (No. 20-1452) and for all the patients included, a written informed consent had obtained in respect of the usage of the images.

\section{RESULTS}

Nine of 11 patients were males and 2 females with a mean age of 33.45 years (range, 19-54 years). The leading symptoms were palpable mass, anal pruritus, perianal pain, and/or anal soiling/discharge. All patients declared gradual enlargement of their lesions,
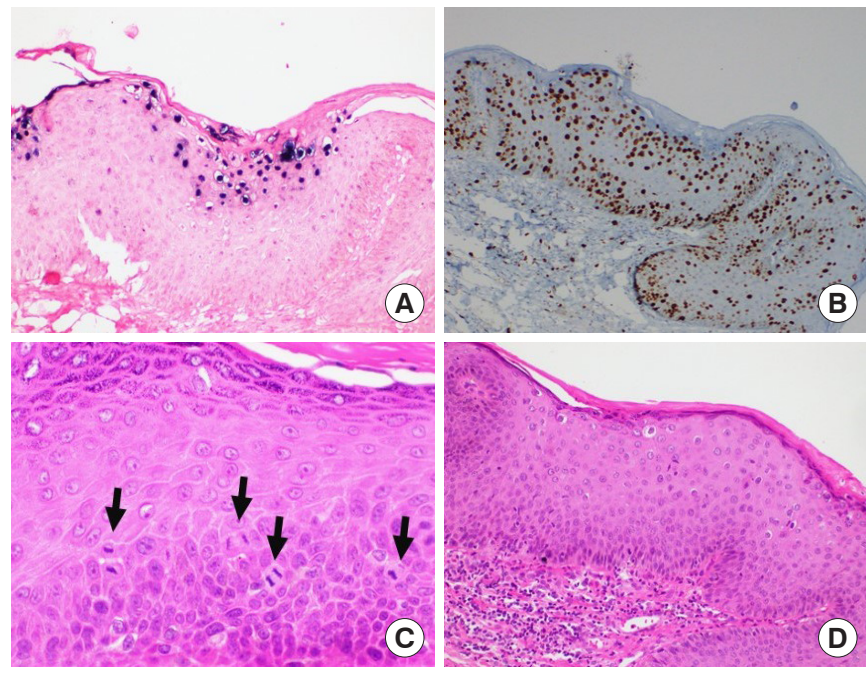

Fig. 3. (A) Human papillomavirus (HPV) low risk positivity (HPV II Family 6 chromogenic in situ hybridization stain, $\times 200$ ). (B) Full thickness Ki-67 labelling (Ki-67 immunohistochemistry, $\times 100$ ). (C) Increased mitosis as marked by arrows (H\&E, $\times 400)$. (D) Mild atypia of the squamous epithelium $(\mathrm{H} \& \mathrm{E}, \times 200)$.

and all of them were told (at least initially) to have anal warts. Two patients declared anal intercourse. None was human immunodeficiency virus-positive. Ten patients had undergone at least 1 nonsurgical therapy at other centers, and 1 of them had undergone a limited surgical resection, all of which were apparently unsuccessful.

Postoperatively, 3 patients developed partial wound/suture dehiscence, which was left to secondary healing. No other specific complications were noted. Although part of the medial suture lines of the flaps extended to the anal verge in many patients, mucosal ectropion was not prominent in any case. We never planned or needed a diverting stoma. A single patient had already undergone a loop sigmoid colostomy at another center, and this was closed 3 months following our standard resection and reconstruction. The median operation time was $90 \pm 20$ minutes and the median blood loss was $30 \pm 10 \mathrm{~mL}$. The patients were discharged in 2 to 7 days, postoperatively. The mean tumor size (maximum length) was $15.54 \pm 1.34 \mathrm{~cm}$ (range, $10-26 \mathrm{~cm}$ ). On pathological examination, all cases were histologically papillomatous lesions with koilocytes. Focal high-grade dysplasia was detected in some specimens, but this didn't correlate with high-risk HPV positivity. None of them had invasion or surgical margin positivity. Eight patients had low-risk HPV positivity, and 3 had high-risk HPV positivity (Table 1). Six patients (54.5\%) felt safe to return to work and sexual activities at 2-month's follow-up, and all of them at 6 months. No anal incontinence developed; on the contrary, most patients experienced better continence, but this was probably due to the elimination of discharge from the bulky tumor. During the mean follow-up period of 50.45 \pm 1.75 months (range, 10-196 months), we haven't detected any recurrences. Only 2 of 3 patients 
Table 1. Patients' overview for histological type, degree of dysplasia, specimen margins, and molecular classification of HPV

\begin{tabular}{lllll}
\hline Patient No. & $\begin{array}{c}\text { Histological } \\
\text { Type }\end{array}$ & $\begin{array}{c}\text { Degree of } \\
\text { dysplasia }\end{array}$ & $\begin{array}{c}\text { Specimen } \\
\text { margin }\end{array}$ & $\begin{array}{c}\text { HPV } \\
\text { subtype }\end{array}$ \\
\hline 1 & LSIL & Condyloma & Negative & Low-risk HPV \\
2 & LSIL & Condyloma & Negative & Low-risk HPV \\
3 & HSIL & Severe & Negative & Low-risk HPV \\
4 & HSIL & High & Negative & Low-risk HPV \\
5 & LSIL & Condyloma & Negative & Low-risk HPV \\
6 & LSIL & Mild & Negative & Low-risk HPV \\
7 & LSIL & Mild & Negative & Low-risk HPV \\
8 & LSIL & Condyloma & Negative & Low-risk HPV \\
9 & LSIL & Mild & Negative & High-risk HPV \\
10 & LSIL & Mild & Negative & High-risk HPV \\
11 & LSIL & Condyloma & Negative & High-risk HPV \\
\hline
\end{tabular}

HPV, human papillomavirus; LSIL, low-grade squamous intraepithelial lesion.

who had satellite warts developed minute penile or pubic lesions during the 1st postoperative year, and these were simply removed or treated with cryotherapy or $\mathrm{CO}_{2}$ laser.

\section{DISCUSSION}

In spite of the discrepancy about the treatment of BLT in clinical practice, our experience strongly suggests that it should be treated as skin cancer. We know that more than $80 \%$ of anogenital warts are associated with low-risk HPV subtypes 6 and 11. On the other hand, anogenital cancers usually carry the DNA of high-risk HPV types 16 and 18, or rarely 52, and 56 [16]. However, condyloma patients might become infected simultaneously with multiple HPV types [17]. Besides, a long-standing genital wart can turn malignant due to the dynamics between the virus and the immunologic response of the host. Improper conduct or disruption of treatment may cause the lesions to repeat, encircle the perianal region, and reach giant dimensions [18]. Immune deficiency status is known to augment the malignant potential of giant warts, and malignant transformation to frankly invasive SCC has been described in a considerable number of patients $[3,19]$. However, foci of invasive cancer within giant condyloma specimens are of uncertain significance, and they do not seem to correlate with recurrence or prognosis. Local invasion and local recurrence are the major sources of morbidity in this disease [4]. In spite of the presence of different types of focal dysplasia in our series, we experienced no recurrences. This might be influenced by the rather noninvasive character of the lesions, negative margins and/or rapid healing with successful reconstruction resulting in very limited inflammation and growth factors [19].

Therefore, from the clinical perspective, it's not fruitful to speculate on the malignant potential of a case with repeated biopsies. If a proctology team is capable of removing the tumor without significant morbidity, this should be the straightforward approach for almost all BLT, as exemplified in this series. As BLT is classified as a verrucous carcinoma, the scarce literature also weighs in favor of radical surgical excision [11, 12]. The advantage of en bloc wide resection with safe margins is the ability to histologically examine the entire specimen to ensure clear margins and to evaluate for foci of SCC. For advanced cases, preoperative imaging to determine infiltration depth and possible infiltration of other tissues may be needed in order to accurately plan the surgical strategy. In addition to the oncologic pitfalls, BLT impairs the patients' quality of life. Repeated hemorrhages may lead to anemia, the vicinity to the anal orifice may lead to tumor infection with the resultant of heavy smell, and anal pruritus and mucous discharge may develop [20]. Our results support the fact that simultaneous reconstructive surgery with excision of the primary tumor provides fast recovery, minimizes anal stricture, and has favorable outcomes in terms of returning back to work, sexual function, and continence. Surgical treatment of BLT requires special expertise. Reconstruction techniques on the perineum are difficult and may add to further problems with additional wounds, bleeding, hematoma, wound infection, or dehiscence [21, 22]. The patient's rapid return to normal life is crucial to the global success of treatment. As a referral team, we have treated many cases of extensive, recurrent pilonidal disease or hidradenitis suppurativa with wide local excision plus simultaneous reconstruction of the perianal region. BLTs are deep, friable masses and some could be extremely vascularized. Certain reports have suggested the benefits of preoperative selective angioembolization of the feeding branches of the internal iliac arteries to decrease the vascularity and minimize blood loss during the excision of such tumors [23]. We never needed such measures, and we never experienced excessive bleeding necessitating blood transfusion. Due to the possible difficulty in resection and reconstruction, it has been suggested that surgical excision may be carried out in a single operation or as staged resection if the size of the condyloma is large ( $>50 \%$ anal circumference) and if the anal canal is involved. Defects can be closed primarily or left to heal as the secondary intention with granulation tissue, or larger wounds may require to be closed with skin grafts [24]. According to our experience, flap reconstruction of the defects at the same session provided the whole surgical treatment be finished with a single admission. If the patient has received radiation or anticipating radiation as adjuvant therapy, vertical rectus abdominis muscle myocutaneous flap was reported to have higher success rates [25]. Our preference was using the V-Y flap, supplemented with other flaps whenever needed.

Although we lack different treatment groups to compare, most of our patients had undergone nonsurgical treatment modalities with almost no success. Possibly due to the difficulty in reconstruction after surgical resection of such big lesions on the stiff and risky sacrogluteal/perianal region, as well as the similarities with smaller, common warts, BLT has been tried to be treated 
with nonsurgical methods with limited success. Treatment with a trichloroacetic acid solution of $80 \%-90 \%$ or podophyllotoxin solution of $0.5 \%$, radiotherapy, chemotherapy, immunotherapy, or cryotherapy, has been suggested but also criticized [5-10, 26]. A few studies also put forward imiquimod as an effective treatment option for BLT $[27,28]$. Although complete clearance of common warts has been observed in $45 \%-56 \%$ of the patients treated with the imiquimod, its efficacy in the treatment of BLT is questionable [29]. In general, the selection of therapy has been suggested to depend on the physical and psychosocial condition in addition to the availability of medical facilities. Size, anatomical location, and the amount and character of the tumor, as well as the presence of comorbidities such as pregnancy and immune system deficiency, were thought to affect the therapy selection. To our belief, all of these treatments are desperate alternatives, based on a strained interpretation of BLT to assume that it is similar to ordinary warts. Complete excision and flap reconstruction are fast, inexpensive, radical, and easy to follow. Adjuvant therapy is not required to prevent postoperative relapses in BLT.

We have to consider BLT as a separate entity from common anogenital warts due to its malignant potential and the morbidity or even mortality it may cause if not treated efficiently. In the hands of dedicated proctology teams, complete excision and flap reconstruction aid in rapid and radical treatment of BLT without any need for further adjuvant measures. We consider aggressive surgery for BLT as standard treatment to maintain the optimal surgical results and prevent recurrence.

\section{CONFLICT OF INTEREST}

No potential conflict of interest relevant to this article was reported.

\section{REFERENCES}

1. Assi R, Reddy V, Einarsdottir H, Longo WE. Anorectal human papillomavirus: current concepts. Yale J Biol Med 2014;87:53747.

2. Dunne EF, Nielson CM, Stone KM, Markowitz LE, Giuliano AR. Prevalence of HPV infection among men: a systematic review of the literature. J Infect Dis 2006;194:1044-57.

3. Safi F, Bekdache O, Al-Salam S, Alashari M, Mazen T, El-Salhat H. Management of peri-anal giant condyloma acuminatum: a case report and literature review. Asian J Surg 2013;36:43-52.

4. Trombetta LJ, Place RJ. Giant condyloma acuminatum of the anorectum: trends in epidemiology and management: report of a case and review of the literature. Dis Colon Rectum 2001;44: 1878-86.

5. Geusau A, Heinz-Peer G, Volc-Platzer B, Stingl G, Kirnbauer R. Regression of deeply infiltrating giant condyloma (Buschke-Lowenstein tumor) following long-term intralesional interferon alfa therapy. Arch Dermatol 2000;136:707-10.
6. Sobrado CW, Mester M, Nadalin W, Nahas SC, Bocchini SF, Habr-Gama A. Radiation-induced total regression of a highly recurrent giant perianal condyloma: report of case. Dis Colon Rectum 2000;43:257-60.

7. Ilkay AK, Chodak GW, Vogelzang NJ, Gerber GS. Buschke-Lowenstein tumor: therapeutic options including systemic chemotherapy. Urology 1993;42:599-602.

8. Redman JF, Turley JT. Failure of chemotherapy in treatment of giant condyloma acuminata (Buschke-Loewenstein tumor). South Med J 1974;67:742-4.

9. Carson TE. Verrucous carcinoma of the penis: successful treatment with cryosurgery and topical fluorouracil therapy. Arch Dermatol 1978;114:1546-7.

10. Dexeus FH, Logothetis CJ, Sella A, Amato R, Kilbourn R, Fitz K, et al. Combination chemotherapy with methotrexate, bleomycin and cisplatin for advanced squamous cell carcinoma of the male genital tract. J Urol 1991;146:1284-7.

11. Chu QD, Vezeridis MP, Libbey NP, Wanebo HJ. Giant condyloma acuminatum (Buschke-Lowenstein tumor) of the anorectal and perianal regions: analysis of 42 cases. Dis Colon Rectum 1994;37: 950-7.

12. Gole GN, Shekhar T, Gole SG, Prabhala S. Successful treatment of buschke-lowenstein tumour by surgical excision alone. J Cutan Aesthet Surg 2010;3:174-6.

13. Darragh TM, Colgan TJ, Cox JT, Heller DS, Henry MR, Luff RD, et al. The lower anogenital squamous terminology standardization project for HPV-associated lesions: background and consensus recommendations from the College of American Pathologists and the American Society for Colposcopy and Cervical Pathology. Arch Pathol Lab Med 2012;136:1266-97.

14. Nagtegaal ID, Odze RD, Klimstra D, Paradis V, Rugge M, Schirmacher P, et al. The 2019 WHO classification of tumours of the digestive system. Histopathology 2020;76:182-8.

15. Practice Bulletin No. 168: cervical cancer screening and prevention. Obstet Gynecol 2016;128:e111-30.

16. de Villiers EM, Fauquet C, Broker TR, Bernard HU, zur Hausen H. Classification of papillomaviruses. Virology 2004;324:17-27.

17. Garland SM, Steben M, Sings HL, James M, Lu S, Railkar R, et al. Natural history of genital warts: analysis of the placebo arm of 2 randomized phase III trials of a quadrivalent human papillomavirus (types 6, 11, 16, and 18) vaccine. J Infect Dis 2009;199:80514.

18. Yaman I, Bozdag AD, Derici H, Tansug T, Reyhan E. Verrucous carcinoma arising in a giant condyloma acuminata (Buschkelowenstein tumour): ten-year follow-up. Ann Acad Med Singap 2011; 40:104-5.

19. Rosen T. Condylomata acuminata (anogenital warts) in adults: epidemiology, pathogenesis, clinical features, and diagnosis [Internet]. Waltham: UpToDate; c2021 [cited 2019 Feb 15]. Available from: https://www.uptodate.com/contents/condylomata-acuminata-anogenital-warts-in-adults-epidemiology-pathogenesisclinical-features-and-diagnosis. 
20. Badiu DC, Manea CA, Mandu M, Chiperi V, Marin IE, Mehedintu $\mathrm{C}$, et al. Giant perineal condyloma acuminatum (Buschke-Lowenstein tumour): a case report. Chirurgia (Bucur) 2016;111:435-8.

21. Hemper E, Wittau M, Lemke J, Kornmann M, Henne-Bruns D. Management of a giant perineal condylomata acuminata. GMS Interdiscip Plast Reconstr Surg DGPW 2016;5:Doc07.

22. Gurbulak EK, Akgun IE, Omeroglu S, Oz A. Giant perianal condyloma acuminatum: reconstruction with bilateral gluteal fasciocutaneous V-Y advancement flap. Ulus Cerrahi Derg 2015;31:170-3.

23. Holubar SD, Yared JE, Forauer A, Balkman J, Pettus J, Bihrle W 3rd. Preoperative angioembolization of Bushke-Lowenstein tumor: an innovative, alternative approach to reduce perioperative blood loss for exceptionally large tumors. Dis Colon Rectum 2015; 58:262-3.

24. Tripoli M, Cordova A, Maggi F, Moschella F. Giant condylomata (Buschke-Lowenstein tumours): our case load in surgical treatment and review of the current therapies. Eur Rev Med Pharmacol Sci 2012;16:747-51.
25. Lefevre JH, Parc Y, Kerneis S, Shields C, Touboul E, Chaouat M, et al. Abdomino-perineal resection for anal cancer: impact of a vertical rectus abdominis myocutaneus flap on survival, recurrence, morbidity, and wound healing. Ann Surg 2009;250:707-11.

26. De Toma G, Cavallaro G, Bitonti A, Polistena A, Onesti MG, Scuderi N. Surgical management of perianal giant condyloma acuminatum (Buschke-Lowenstein tumor): report of three cases. Eur Surg Res 2006;38:418-22.

27. Anissa Z, Houda HG, Wafa K, Olfa M, Rym BM, Achraf D, et al. Successful treatment with topical imiquimod of anal BuschkeLowenstein tumor in a child. Dermatol Ther 2015;28:363-5.

28. Sonthalia S, Gandhi V, Agrawal M, Sharma P. Successful nonsurgical treatment of penile Buschke-Lowenstein tumor with 12 weeks of 5\% imiquimod alone. Int J STD AIDS 2019;30:1136-9.

29. Combaud V, Verhaeghe C, El Hachem H, Legendre G, Descamps P, Martin L, et al. Giant condyloma acuminatum of the vulva: successful management with imiquimod. JAAD Case Rep 2018; 4:692-4. 